\title{
Russellosaurus coheni n. gen., n. sp., a 92 million-year-old mosasaur from Texas (USA), and the definition of the parafamily Russellosaurina
}

\author{
M.J. Polcyn ${ }^{1, *} \&$ G.L. Bell Jr. ${ }^{2}$
}

1 Shuler Museum of Paleontology, Southern Methodist University, Dallas, Texas 75275, USA.

2 Guadalupe Mountains National Park, Salt Flat, Texas 79847, USA.

* Corresponding author. Email: mpolcyn@mail.smu.edu

Manuscript received: November 2004; accepted: January 2005

\begin{abstract}
A new mosasaur, Russellosaurus coheni, is described from the Collignoniceras woollgari Zone (lower Middle Turonian) at Cedar Hill, Dallas County, Texas. At approximately $92 \mathrm{Ma}$, it is the oldest well-preserved mosasaur skull from North America. It possesses characters diagnostic of Plioplatecarpinae but retains numerous plesiomorphies as well. Phylogenetic analysis indicates a close relationship with Yaguarasaurus columbianus, and these two, together with Tethysaurus nopcsai, form a clade that occupies a position basal to the divergence of the subfamilies Tylosaurinae and Plioplatecarpinae. Russellosaurus coheni is proposed as the nominal taxon of a new mosasaur clade, parafamily taxon novum Russellosaurina, which includes Plioplatecarpinae, Tylosaurinae, their common ancestor and all descendants. Tethysaurus retains a plesiopedal limb and girdle morphology, and along with Russellosaurus and Yaguarasaurus, cranial plesiomorphies. Dallasaurus turneri, a temporally and geographically sympatric plesiopedal mosasaur, occupies a basal position within Mosasaurinae. This phyletic arrangement confirms that marine adaptations, such as development of paddle-like limbs, occurred independently in at least two lineages of mosasaurs, once within Mosasaurinae and once within Russellosaurina.
\end{abstract}

Keywords: Mosasaur, Plioplatecarpinae, Tethysaurus, Turonian, Yaguarasaurus

\section{Introduction}

We here describe a new mosasaur from the lower Middle Turonian (92 Ma) of north-central Texas on the basis of a nearly complete skull discovered at a housing construction site in 1992 by Mark Cohen, a member of the Dallas Paleontological Society. This new specimen represents the oldest, wellpreserved mosasaur skull from North America.

Mosasaurs are a large and diverse group of marine lizards whose evolutionary history spanned the entire Upper Cretaceous. The fossil record of pre-Coniacian mosasaurs is poor. Although the beginning of the Cenomanian to the Coniacian encompasses nearly eight million years, that interval is represented by a small number of specimens, mostly fragmentary and poorly preserved, creating significant gaps in our knowledge of the early evolutionary history of the group. The vast majority of mosasaur fossils are known from sediments of Coniacian through Maastrichtian age. As a result the interrelationships of these more derived forms are well supported in numerous systematic and phylogenetic studies (Russell, 1967; Bell, 1993, 1997; Carroll \& de Braga, 1992; de Braga \& Carroll, 1993). Most of these specimens fall into four well-established clades, viz. the subfamilies Mosasaurinae, Tylosaurinae, and Plioplatecarpinae and the taxon Halisauromorpha (sensu Bell, 1993). Two Turonian forms, Angolasaurus bocagei (Antunes, 1964; Lingham-Soliar, 1994) and Yaguarasaurus columbianus (Parámo, 1994, 2000) are closely allied with Plioplatecarpinae.

In recent years, basal mosasauroids from the Adriatic region have been redescribed and considered by some workers to constitute a monophyletic group, the Aigialosauridae (Carroll 
\& DeBraga, 1992; DeBraga \& Carroll, 1993; Caldwell, 1995, 2000). Additionally, work on relatively derived Turonian forms from South America (Páramo, 1994, 2000) and Africa (Bardet et al., 2003) focused on the plesiomorphic nature of those specimens, citing them as morphological intermediates between Aigialosauridae and more derived forms. Underlying these analyses is the concept of a monophyletic Aigialosauridae, although Aigialosauridae is defined primarily on the basis of plesiomorphies, such as retention of terrestrial limbs. Contrary to those studies, Bell (1993, 1997; see also Caldwell, 1996) found Aigialosauridae to be paraphyletic.

The new taxon described herein, along with other Turonian mosasaurs from Africa and North and South America, provide the basis for a phylogenetic analysis employing an expanded data set. The analysis finds aigialosaur-grade mosasaurs to be more closely related to well-established subfamilies than previously considered and suggests that limb modification into a paddle-like structure occurred multiple times within Mosasauroidea. The term 'aigialosaur-grade mosasaur' as used previously (Polcyn et al., 1999) defines a morphological grade of limb development but suffers from an implicit phylogenetic connotation. In light of the growing evidence for a paraphyletic Aigialosauridae, we introduce new terminology hereafter employing the term 'plesiopedal' to identify forms retaining an essentially terrestrial limb and girdle configuration and the term 'hydropedal' for forms possessing a limb and girdle that has evolved into a paddle-like structure.

\section{Institutional abbreviations}

SMU - Shuler Museum of Paleontology, Southern Methodist University; DPS - Dallas Paleontological Society.

\section{Age and geological context}

The specimen comes from the Arcadia Park Shale, approximately $15 \mathrm{~cm}$ above the Kamp Ranch Limestone, SMU locality 259 (Fig. 1), which lies in the Collignoniceras woollgari Zone (ca. $92 \mathrm{Ma}$ ). Fragmentary specimens from the Kamp Ranch Limestone are known from two other localities in the Dallas area. For detailed discussion of the age and stratigraphy of the locality see Jacobs et al. (2005a, b).

\section{Systematic palaeontology}

\section{Order Squamata}

Superfamily Mosasauroidea

Family Mosasauridae

Parafamily Russellosaurina n.

Type genus - Russellosaurus n. gen.

Included taxonomic units - The subfamilies Tylosasaurinae and Plioplatecarpinae and their sister-clade containing the genera Tethysaurus, Russellosaurus and Yaguarasaurus.

Definition - All mosasaurs more closely related to Tylosaurinae and Plioplatecarpinae, the genus Tethysaurus, their common ancestor and all descendants than to Mosasaurinae.

Diagnosis - Unfused haemal arches, pterygoid process of basisphenoid thin and broadly fan-shaped with posterior extension of articular surface causing a more lateral orientation, triangular tabular boss present on posterior ventral midline just anterior to the frontoparietal suture, jugal posteroventral process present, teeth striate medially.
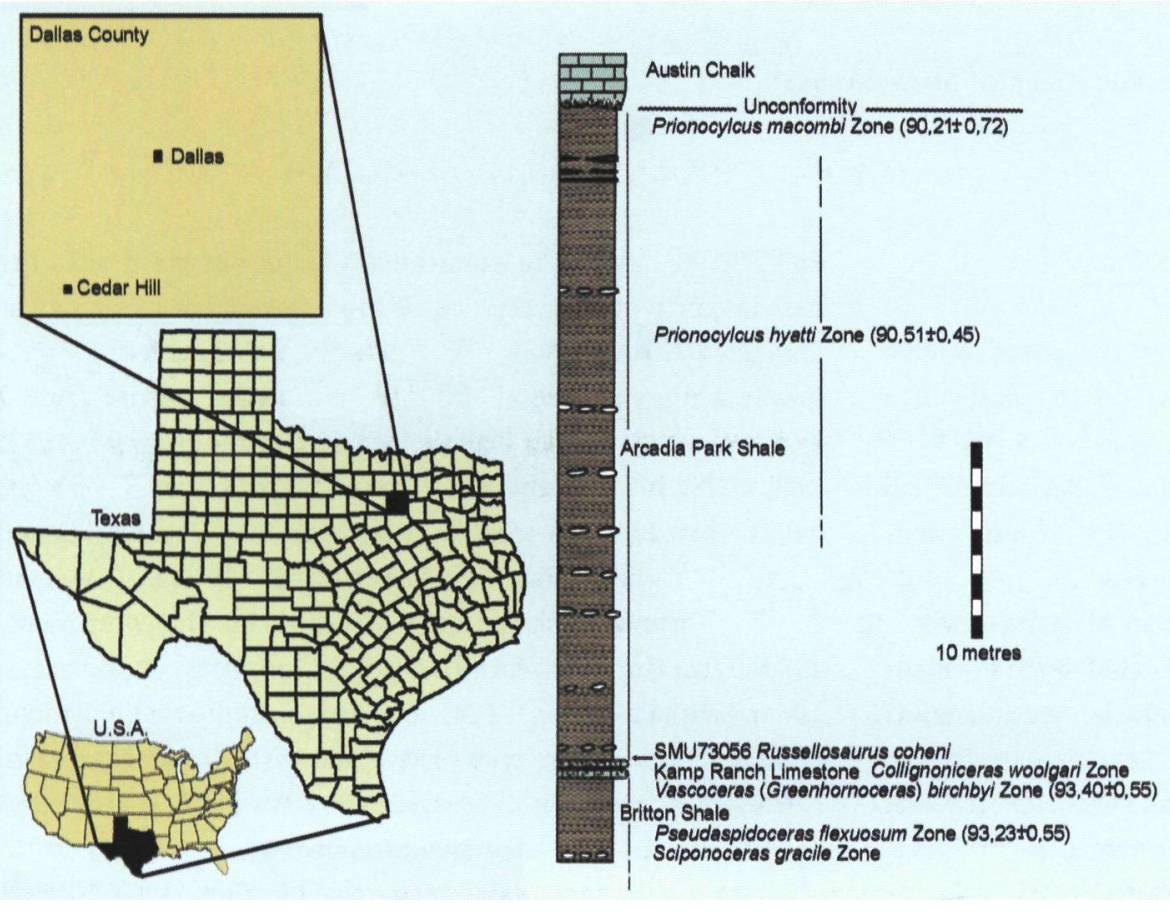

Fig. 1. Locality map of Dallas County (Texas, USA), indicating general location and stratigraphic horizon for Russellosaurus coheni $n$. gen., $n$. sp. (specimen SMU73056) and locality SMU 259. The Britton Shale Member rests on the Tarrant Member, which in turn, rests on the Woodbine Formation. 
Remarks - The parafamily Russellosaurina is erected here to give identity to the monophyletic grouping of Tylosaurinae plus Plioplatecarpinae and closely related forms that are consistently reconstructed in cladistic analyses of mosasaurs (LinghamSoliar, 1988; de Braga, 1990; de Braga \& Carroll, 1993; Bell, 1993, 1997). Russell (1967) also considered Plioplatecarpinae and Tylosaurinae to be more closely related to each other than the other subfamilies. The current study reconstructs a clade containing Tethysaurus, Russellosaurus and Yaguarasaurus as the unnamed sister taxon to Plioplatecarpinae plus Tylosaurinae. These two nominal subfamilies have strong support as sister taxa and Russellosaurina thus has utility in a dichotomously branching phylogenetic system. Taxon Russellosaurina supercedes previous references to 'Russellosaurinae' (Bell, 1997) which had been used in an informal sense, but did not adhere to ICZN rules without further changes to otherwise stable subfamily-level names.

\section{Genus Russellosaurus n. gen.}

Etymology - In honour of Dale Russell for his landmark work on mosasaur morphology and systematics and his numerous contributions to palaeontology.

Type species Russellosaurus coheni n. sp.

Diagnosis - Small, lightly built mosasaur, frontal narrow with a length to width ratio of 1.6:1. Sixteen maxillary teeth and 16 dentary teeth. Anterior premaxilla broad and blunt, in dorsal view the premaxillary-maxillary suture is oblique. The ectopterygoid lightly built and comprised of a distinct small subrectangular pterygoid process and a slender rod-like jugal process. Incipient emargination of the frontal by the external nares. A pair of foramina separated by a thin median septum in the floor of the basioccipital are interpreted as the entrance of the basilar artery, and exit the ventral surface of the basioccipital as multiple small and anteriorly placed foramina. Extreme downgrowth of the pterygoid processes of the basisphenoid. Lightly built postorbitofrontal processes. The pineal foramen is located in the centre of the triangular parietal table. The supraoccipital loose cartilaginous contact with parietal. Median cleft in posterior parietal margin in dorsoventral aspect.

Russellosaurus coheni n. sp.

Etymology - In honour of Mark Cohen of the Dallas Paleontological Society, who discovered and generously donated the specimen.

Holotype - Nearly complete, disarticulated skull, SMU73056, housed at the Shuler Museum of Paleontology at Southern Methodist University.
Type Locality - SMU locality number 259, Cedar Hill, Dallas County, Texas.

Type Horizon - Upper Cretaceous, Middle Turonian (92 Ma), Arcadia Park Shale, approximately $15 \mathrm{~cm}$ above Kamp Ranch Limestone (for detailed discussion see Jacobs et al., 2005a, b).

Diagnosis - As for genus.

\section{Description}

The specimen preserves most elements of the skull but none of the post-cranial skeleton. The preservation is generally good, although the specimen is crushed and finely fractured, and some crushing and plastic deformation has occurred, most obviously in the basicranium. The specimen appears to be a subadult animal based on lack of fusion of the elements of the braincase and extreme vascularization of the bone surface suggesting the animal was in a rapid growth stage.

Premaxilla - The premaxilla lacks the posterior portion of the internarial bar and the two anterior teeth are broken proximal to the enamel-bearing portion. The posterior two teeth are missing, but represented as empty sockets (Fig. 2A - C). A predental rostrum is absent and the anterior premaxilla is semicircular in dorsal view. In lateral view, the premaxilla rises vertically from the tooth line then curves abruptly to nearly horizontal, as does the maxillary suture, approximately parallelling the dorsal margin in lateral view. The premaxilla contains four tooth positions set in subcircular recesses, a thin ridge of bone forming a border around the alveolar recess. A resorption pit is present posteromedial to the left anterior tooth. The ventral median ridge is broken posteriorly but is fused at the midline. The internarial bar is broken $1.5 \mathrm{~cm}$ posterior to the tooth-bearing portion and at the point of breakage the transverse extent of the internarial bar is approximately $50 \%$ of the maximum width of the dentigerous portion. It is roughly rectangular in cross section with a weakly developed descending median ridge, the anterior extent of the ridge terminating between the posterior two tooth positions. The entrance of the premaxillary branch of the facial nerve is visible on the broken posterior surface of the internarial bar indicating entrance at least posterior to the middle of the second maxillary tooth position. The nerve exits are variably placed on the dorsal surface and number seven in total, three on the left, four on the right. The inferred position of articulation with the vomers is unusually far forward and set between the posterior two teeth.

Maxilla - Both maxillae have sixteen tooth positions (Fig. 2D - G). The teeth in positions 6-9 are the longest. All marginal teeth are relatively slender, uniformly tapered and moderately recurved, with fine medial striations. The posterior portion of 


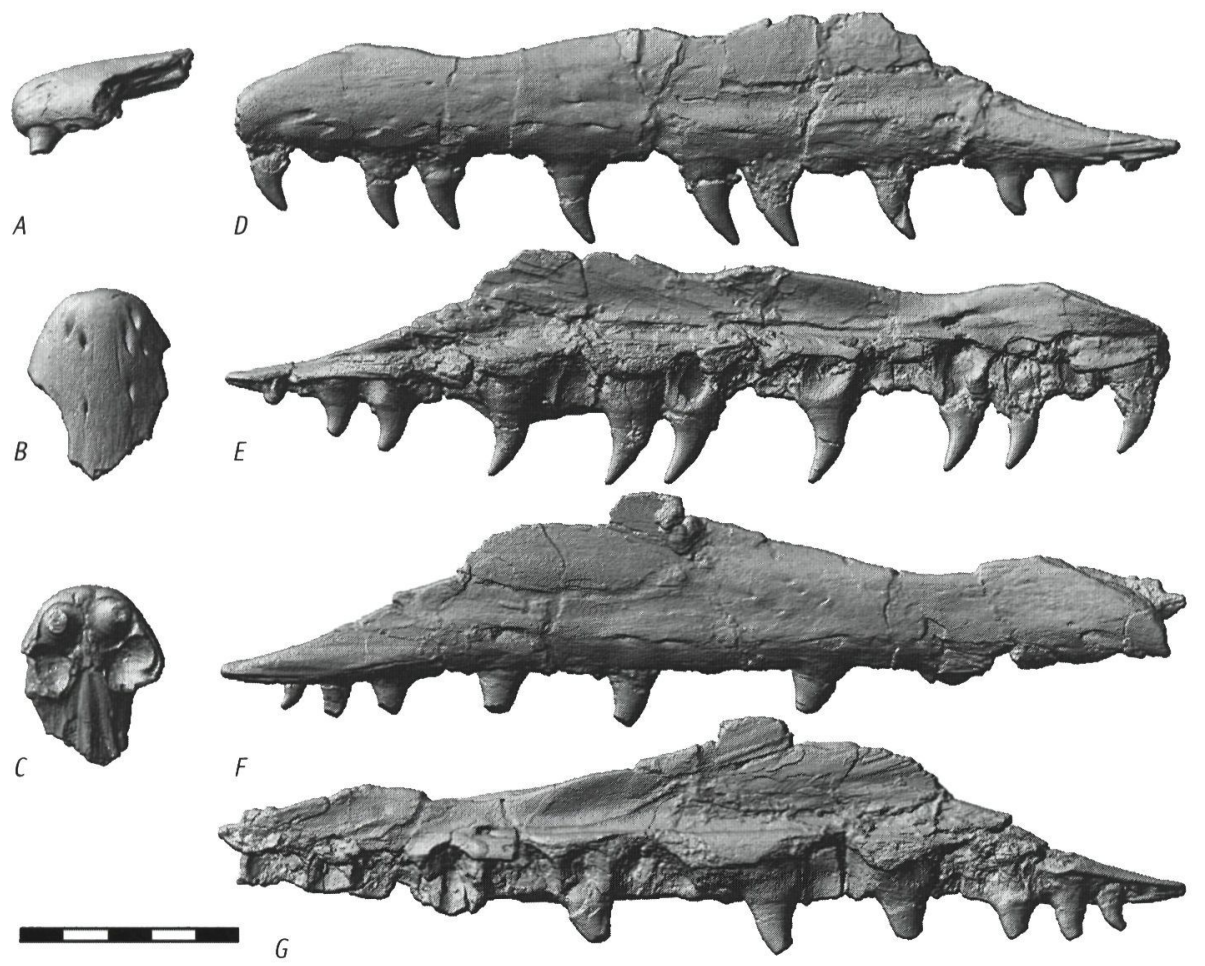

Fig. 2. Russellosaurus coheni $n$. gen., n. sp. (SMU73056); $A$ - premaxilla in lateral; $B$ - dorsal; and $C$ - ventral views; left maxilla in D - lateral; and $E$ - medial views; right maxilla in $F$ - lateral; and $G$ - medial views. Scale bar equals $5 \mathrm{~cm}$.

the maxillae extends posterior and underlies the anteroventral orbit. The medial parapet where preserved is relatively short, the tooth roots almost completely exposed in lingual view. The teeth are cemented to the maxillary shelf and lateral wall by large bony bases of attachment. Shallow resorption pits are generally posterolingual in the posterior third but in the anterior two-thirds the roots are deeply excavated lingually in advanced stages of resorption. Tooth presence in the left maxilla follows a pattern of $1, x, 3,4, x, 6, x, 8,9, x, 11, x$, $13,14, x, 16$ (where $x$ indicates the absence of a tooth). An accurate reconstruction for the right maxilla is unavailable due to disarticulation of individual teeth and attached roots. The anterior terminus of the external nares lies dorsal to a point between the second and third tooth positions, the lateral margin of the nares forming a deep emargination between the third and seventh or eighth tooth position where it forms an inflection point, behind which it forms a second shallower emargination which reaches its posterior terminus at a position dorsal to the eleventh tooth. In dorsal view, this condition causes the anterior portion of the external nares to display a more lateral expansion relative to the posterior portion. Medially, the maxillary branch of the facial nerve and maxillary artery enter dorsal to the twelfth tooth position and exit dorsal to the fourth. The facial nerve exits on the lateral surface as a linear row of approximately eleven foramina, parallelling the ventral border of the maxilla.

Frontal - The frontal (Fig. 3E, L) is long and narrow, the midline length as preserved is $146 \mathrm{~mm}$ and the maximum width is $91 \mathrm{~mm}$. The interorbital width is $49 \mathrm{~mm}$. There is no indication of a raised median dorsal ridge. In dorsal outline, the lateral margins of the anterior two-thirds form a triangle, while the posterior third is subrectangular and slightly constricted between the orbits. Posterolaterally, sharp-pointed, arcuate lateral projections (alae) are present anterior to the frontoparietal suture. The anterior portion is somewhat damaged with no evidence of articulation for nasals but retains evidence of a median cleft, presumably to receive the posterior premaxilla. The anterolateral border is slightly emarginated by a notch that forms the posterior terminus of the external nares. Anterior to the notch the lateral frontal forms the posteromedial narial emargination. The ventral articulation with the prefrontal is formed by a semicircular ridge of bone that accepts the posteriorly directed process of the prefrontal and an anterior overlapping suture. The prefrontal and postorbitofrontal sutures are separated by a distance of $15 \mathrm{~mm}$, demonstrating there was no contact between these elements. Ventrally, the descending processes narrow, almost to enclose the olfactory canal at a point medial to the posterior terminus of the prefrontal. On the posteroventral portion, a pair of posteriorly diverging sulci, presumably to receive connective tissue from the orbitosphenoids, are present and well developed. These bound a triangular tabular median boss near the frontoparietal suture. The frontoparietal suture is roughly transverse without posteromedial projections onto the parietal. In posterior view, the frontal displays a medial area of strong vertical comb-like sutures where it joined the parietal. Laterally an oblique groove, sloping dorsolaterally and emerging laterally nears the dorsal tips of the frontal alae, and accepts a corresponding flange of the parietal. The ventral walls of the groove form posteroventral flange-like processes embracing the parietal flange from below. 
Parietal - The parietal table is triangular in dorsal view with a moderately sized pineal foramen ( $7 \mathrm{~mm}$ diameter) located approximately in the middle of the table (Fig. 3D, M). The posterior apex of the triangle is not complete, the two sides diverge posteriorly forming the edges of a parasagittal ridge. The rami originate under the parietal table, posterior to the parietal foramen, and terminate as a bifurcated arch that overlies the supratemporals, the medial portion of which is

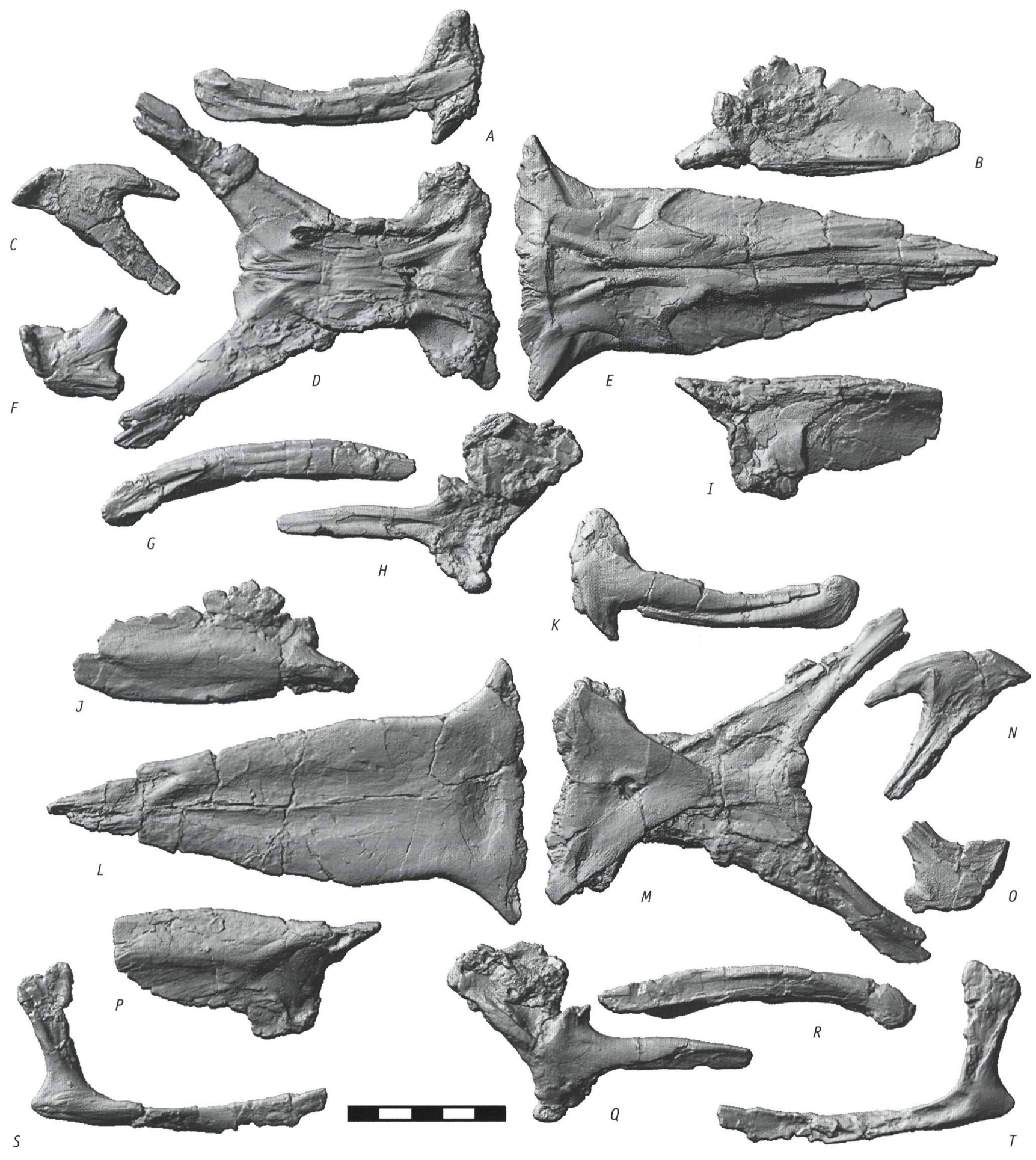

Fig. 3. Cranial elements of Russellosaurus coheni n. gen., $n$. sp. (SMU73056), left squamosal and postorbitofrontal in $A$ - medial; and $K$ - lateral views; right prefrontal in $\mathrm{C}$ - medial; and $\mathrm{J}$ - lateral views; left supratemporal in $\mathrm{C}$ - lateral; and $\mathrm{N}$ - medial views; parietal in $D$ - ventral; and $M$ - dorsal views; frontal in $E$ - ventral; and $L$ - dorsal views; right supratemporal in $F$ - lateral; and $O$ - medial views; left squamosal in $G$ - medial; and $R$ - lateral views; left postorbitofrontal in $\mathrm{H}$ - medial; and $Q$ - lateral views; left prefrontal in I - medial; and $P$ - lateral views; jugal in $S$ - lateral; and $T$ - medial views. Scale bar equals $5 \mathrm{~cm}$. 
more vertically oriented and the lateral more horizontally oriented. The bifurcation continues anterior as a distinct narrow groove for a distance of at least three centimetres. Ventrally, the suture, in the form of a groove, runs obliquely across the horizontally flattened parietal ramus and terminates at the lateral border. This is apparently a loosely articulating suture. The posterolateral margin of the ramus barely contacts the squamosal laterally, but both the ramus and the squamosal display rugosity indicating the presence of connective tissue. In dorsal view the convergence of the medial margins of the rami form a broadly open concavity, the depth of which equals one-third the total length of the parietal. The apex of the concavity displays short, broad posterior protuberances on either side of the parasagittal ridge. Thin, shallow, descending processes originate just posterior to the frontal suture and extend posteriorly four-fifths of the sagittal length. A descending structure that appears to be a posterior extension of the frontal tabular boss, originates at the frontal suture and straddles the pineal foramen, its sides converging posteriorly to form ridges that extend to the posterior margin. At this point there is a small semicircular cleft formed between the two posterior protuberances noted above.

Prefrontal - The prefrontal does not have a pronounced 'wing' but forms a more vertical lateral surface (Fig. 3B, I, J, P). A low rounded longitudinal ridge extends from the posterodorsal termination approximately centered on its lateral surface. The articulation with the palatine appears to have been a typical semicircular interdigitating sutural area, but is proportionally smaller than in other derived mosasaurs. The articulation with the ventrolateral frontal is a long narrow triangular interdigitating suture anteriorly and a posterior process that inserts into a recess on the ventral frontal posteriorly. The maxilla was separated from the frontal by the prefrontal.

Postorbitofrontal - The left postorbitofrontal is complete, the supraoccipital is crushed in such a way as to sandwich the anteromedial process, the right lacks the anteromedial process (Fig. 3A, H, K, Q). The postorbitofrontal clasps the frontoparietal suture, the anterior projection lies lateral to and under the frontal inserting into a well-defined recess, the posterior medial process joins the parietal in a lateral suture. There is a small recess in the anterolateral portion of the parietal to accept a corresponding peg-like structure from the postorbitofrontal. The parietal articulation extends only a very short distance medially. The posterior process inserts into a longitudinal channel in the dorsal squamosal. A prominent lateral ridge parallels the lateral margin and extends onto the ventrolateral process. Ventrally, the squamosal articulation is visible anteriorly to about the anterior margin of the supratemporal fenestra. Viewed ventrally, the ventrolateral process possesses a prominent ridge parallelling the anterior border and forms a loose articulation with the jugal.
Jugal - The jugal is an L-shaped bone articulating with the maxilla and lacrimal anteriormedialy, the postorbitalofrontal dorsolaterally, and the ectopterygoid posteromedially (Fig. 3S, $\mathrm{T})$. The posteroventral process is strongly developed and displays deep striations and ridges. The articulation with the ectopterygoid is in the form of an elongate, tear-shaped groove. The articulation with the postorbitofrontal was restricted to the anterodorsal portion of the dorsal ramus.

Squamosal - Both squamosals are nearly complete. The right is free of matrix and the left is in contact with the right postorbitofrontal obscuring part of its lateral surface (Fig. 3A, $G, K, R)$. The anterior border of the squamosals contains a longitudinal recess to accept the postorbitofrontal from above. The squamosal thickens posteriorly to the point of contact with the supratemporal. The medial articulating surface of the squamosal has a longitudinal trough to accept a corresponding ridge-like process from the supratemporal. Laterally, the posterior termination of the squamosal is teardrop shaped, its surface is highly rugose, does not have a dorsal process and the ventral process is extremely small. Posteroventrally, the squamosal shares the support of the quadrate with the supratemporal. A gently rounded ridge originates in about the middle of the lateral side of the posterior expansion, thins to a low sharp ridge just lateral to the anterior articulation with the supratemporal, and extends forwards at least two-thirds the length of the element.

Palatine - Both palatines are present but somewhat crushed (Fig. 4C, E, I, K). They are unusually long and slender, and appear to have extended posteriorly no further than the posterior termination of the maxilla. The anterior extent is unknown due to breakage. The anteromedial process is oriented obliquely and is slightly curved dorsoventrally. The superior portion forms a very high thin crest that extends posteriorly to the prefrontal suture. The pterygoid articulation is a slightly overlapping flange that occurs only on the posteromedial corner forming a loose oblique articulation. The maxillary articulation is a normal elongate groove. The choanal opening is extremely narrow. The vomers are present but unremarkable other than the extreme anterior articulation with the premaxilla.

Pterygoid - The pterygoid has eleven tooth positions (Fig. 4A, $\mathrm{D}, \mathrm{H}, \mathrm{J})$. The teeth are almost circular in cross section based on the maximum diameter at the base. The teeth gradually increase in size posterior to anterior with the second or third position being the largest. The teeth are broken and nothing can be said of their recurvature, length, striations or carinae. The teeth are set in a shallow trough and strongly cemented medially. The lateral surface of the base of attachment is clearly visible as the lateral wall rises only slightly. The implantation is pleurodont. The dentigerous portion is low, unlike tylosaurines and derived plioplatecarpines. The articulation with the palatine 


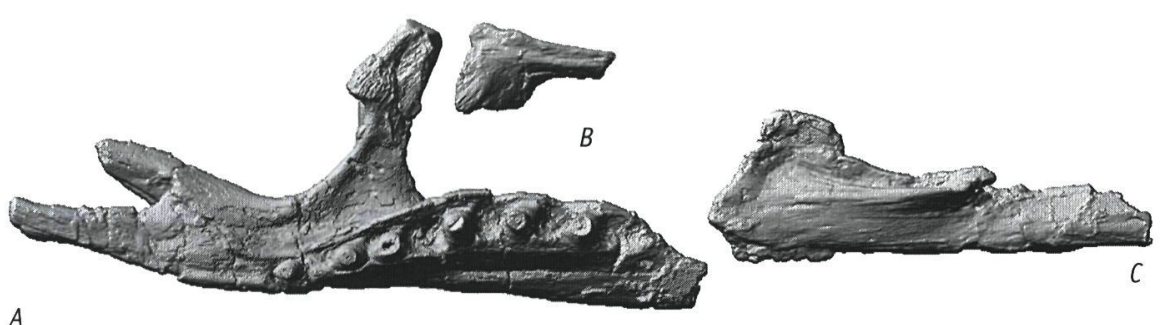

A
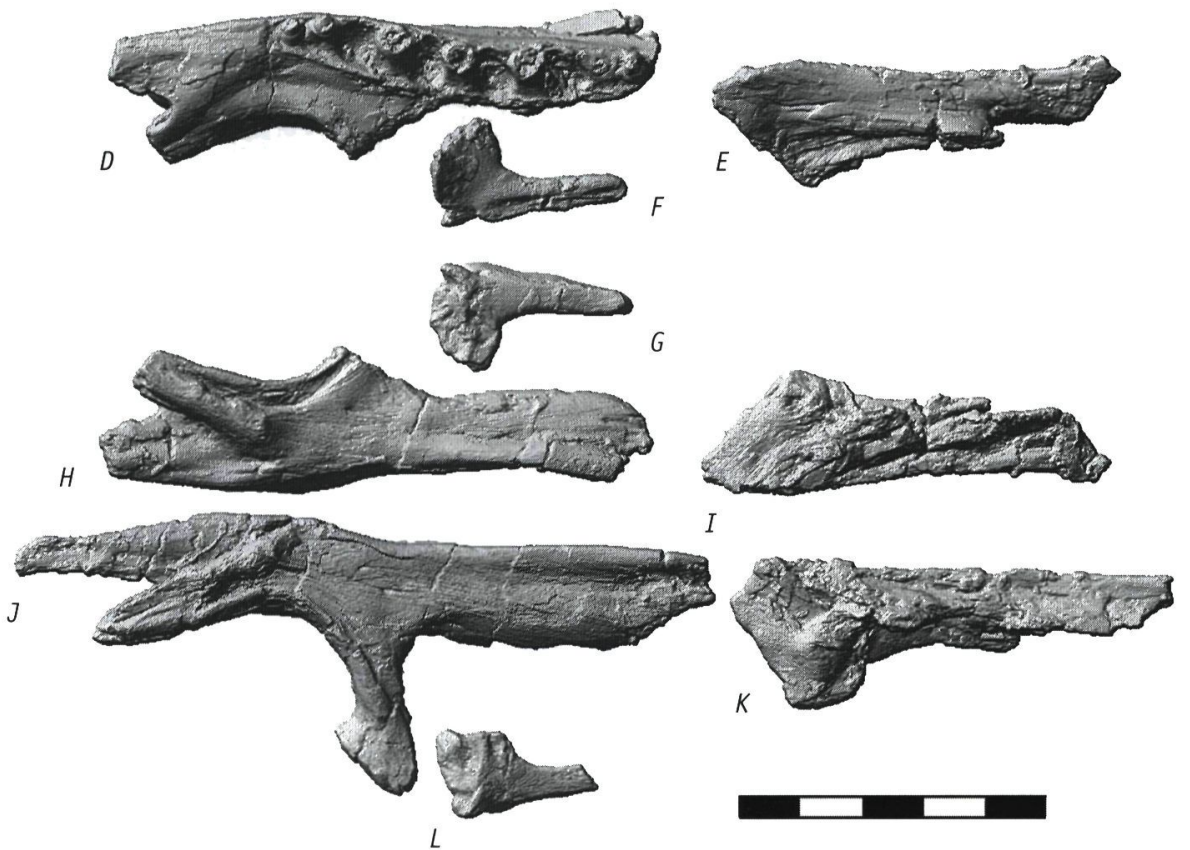

Fig. 4. Palatal elements of Russellosaurus coheni $n$. gen., n. sp. (SMU73056), right pterygoid in A - ventral; and J - dorsal views; right ectopterygoid in $B$ - ventral; and $L$ - dorsal views; right palatine in $C$ - ventral; and $K$ - dorsal views; left pterygoid in D - ventral; and $H$ - dorsal views; left ectopterygoid in $F$ - ventral; and $G$ - dorsal views; left palatine in $I$ - ventral; and $E$ - dorsal views. Scale bar equals $5 \mathrm{~cm}$.

is oblique but the precise anterior extent of the articulation is unclear due to damage. The basisphenoid process is very long although the distal portion is missing. The quadratic rami of the pterygoids are broken and missing.

Ectopterygoid - The ectopterygoids are both preserved (Fig. $4 B, F, G, L)$. The element is comprised of two distinct parts, a thin subrectangular block that underlies the lateral ramus of the pterygoid and a rod-like anterior projection that articulates laterally with a shallow groove in the medial jugal. It is long and slender antero-posteriorly unlike other plioplatecarpine mosasaurs.

Basioccipital - The basioccipital is slightly crushed and distorted (Fig. 5G, H). The condyle is broad and flat and has a broad ventral exposure of the articular surface. Paired arterial canals presumably for the basilar arteries, enter the floor of the medullary cavity separated by a thin medial septum and exit via two large foramina on the ventral basioccipital posterior to the basisphenoid suture. The ventrolaterally oriented basal tubera are well developed, elongate and rectangular in cross section, are inclined anteroventrally and articulate anteriorly with the ventroposterior processes of the basisphenoid.

Basisphenoid - The sella turcica is narrow and deep, forming high lateral walls that would have cradled the pituitary gland
(Fig. 5E, F). A branch of the internal carotid artery emerges in its centre as an elongate foramen just anterior to the dorsum sellae; however, some damage is present and it is unclear if a median septum was present. The dorsum sellae is relatively higher and bears two foramina for the abducent nerve (nerve VI) well away from the posterior margin on its lateral margin. The vidian canal is enclosed laterally by a thin sheath of bone. Posteriorly, the vidian canal appears to be a single foramen but anteriorly is bipartite, separated by a thin septum. Ventrally, the basipterygoid processes are large and fan shaped, their medial convergence forming a deep trough. This trough expands posteriorly to form a triangle bearing a thin medial ridge that extends onto the parasphenoid rostrum. The ventroposterior processes tightly overlap the basal tubera of the basioccipital forming a U-shaped suture in ventral view, exposing a large area of the ventral basioccipital. The anterior parasphenoid is broken and missing but the remaining portion indicates a near-vertical orientation.

Prootic - The alar process of the prootic is long and blade-like and bears striae on it lateral terminus indicating a ligamentous attachment to the descending processes of the parietal (Fig. 5A, B). The trigeminal notch is broadly rounded and the supratrigeminal process is small. A strongly developed otosphenoidal crest covers the lateral exit of the seventh nerve. 
Opisthotic - The opisthotic is long and slender (Fig. 5C, D). A strong ridge of bone, emanating from the posterodorsal surface and continuing medially forms a strong overhanging shelf-like structure at the lateral margin of the foramen magnum. We refer to this process as the supraoccipital crest of the opisthotic. The posterior ridge of the X, XI and XII nerve exit does not converge with the posterior ridge of the stapedial canal as in Platecarpus. There is a single exit for the twelfth nerve. A foramen is present just lateral to the oval window in the stapedial groove. Medially, the twelfth nerve emerges via three foramina, however, the posterior two are more dorsally oriented than in Platecarpus (Russell, 1967).

Supratemporal - The supratemporal is roughly T-shaped (Fig. $3 \mathrm{C}, \mathrm{F}, \mathrm{N}, 0$ ). The basal process loosely inserts into the recess formed by the prootic and exoccipital. It is rectangular in
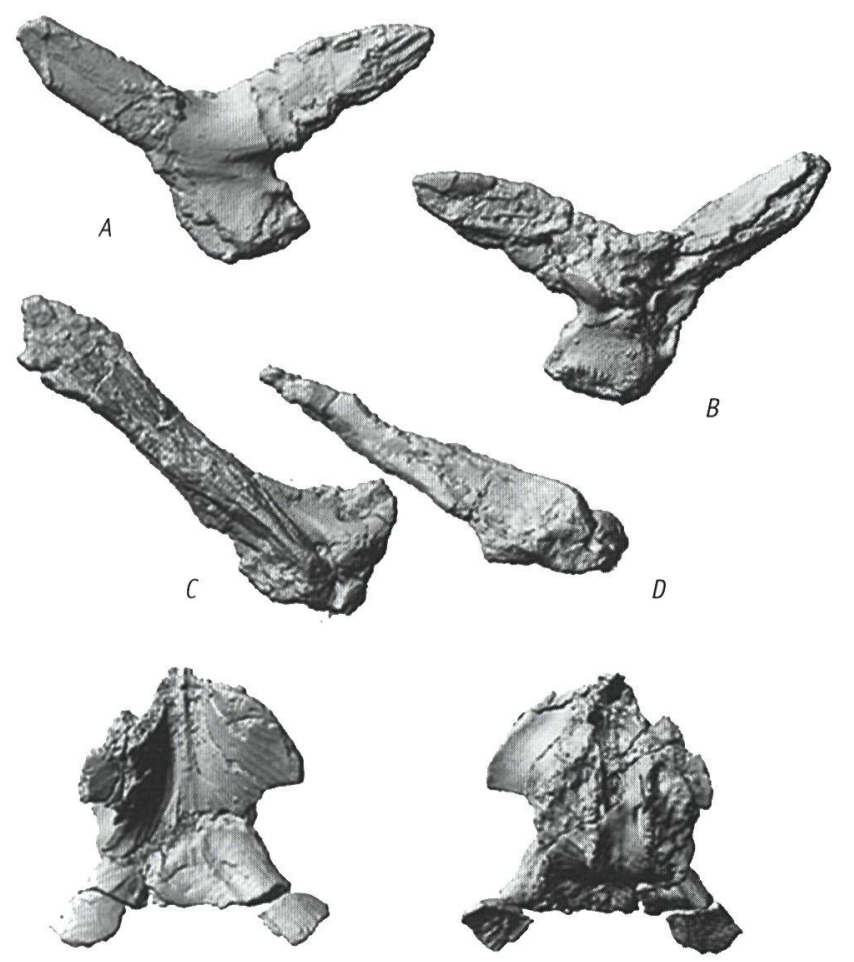

E

F
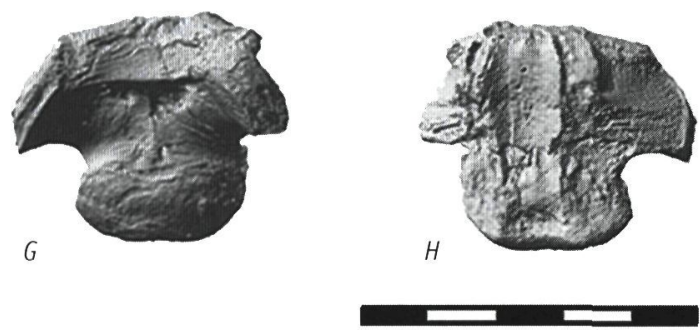

Fig. 5. Basicranial elements of Russellosaurus coheni n. gen., n. sp. (SMU73056), right prootic in A - lateral; and B - medial views; right opisthotic in C - lateral; and D - medial views; basisphenoid in $E$ - ventral; and $E$ - dorsal views; basioccipital in $G$ - ventral; and $H$ - dorsal views. Scale bar equals $5 \mathrm{~cm}$.
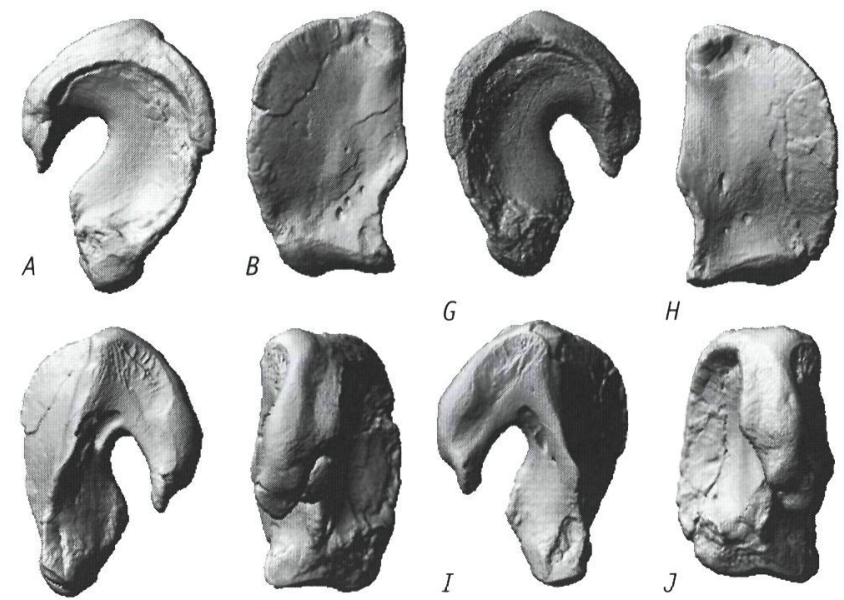

H

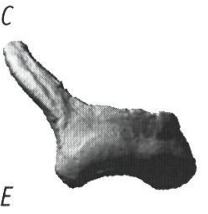

$D$
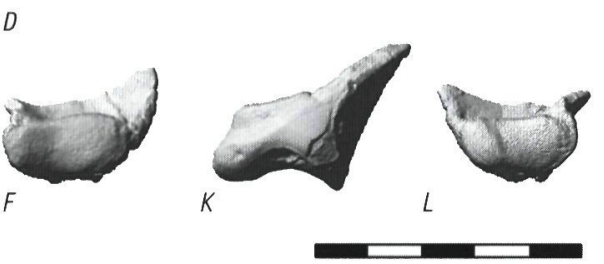

了

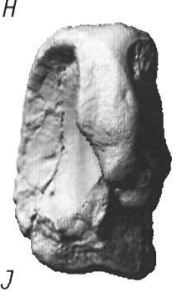

Fig. 6. Quadrates of Russellosaurus coheni $n$. gen., n. sp. (SMU73056), right quadrate in $A$ - lateral; $B$ - anterior; $C$ - medial; $D$ - posterior; $E$-dorsal; and $F$ - ventral views; left quadrate in $G$ - lateral; $H$ - anterior; $I$ - medial; J - posterior; $K$-dorsal; and $L$ - ventral views. Scale bar equals $5 \mathrm{~cm}$.

cross section and decreases in diameter distally. The main body and the anterior parietal process articulates with the squamosal laterally and the parietal above and medially. The posterior process forms a small lateral expansion to facilitate the quadrate articulation.

Stapes - One stapes is preserved. It was broken at the midpoint due to expansion of the surrounding matrix, so an accurate maximum length cannot be given. The minimum length is $40 \mathrm{~mm}$, assuming some missing fragment between the two preserved portions.

Quadrate - Both quadrates are present and well preserved (Fig. 6A - L) and display a long suprastapedial process with parallel dorsal borders. Medially, the suprastapedial process has a broadly rounded ridge extending from dorsal to the stapedial pit. The infrastapedial process is poorly developed, represented by only a small, thin crest of bone. The stapedial pit is long and narrow with moderate medial constriction. The posteroventral ascending tympanic rim is high and elongate. The quadrate conch forms a shallow concavity. The dorsal and central median ridge forms a thin high crest. The ventral portion is a single thin ridge. The ventral condyle is saddle shaped in anterior view and does not form a convex surface. An ossified tympanium is present in medial view but has not been fully prepared. 


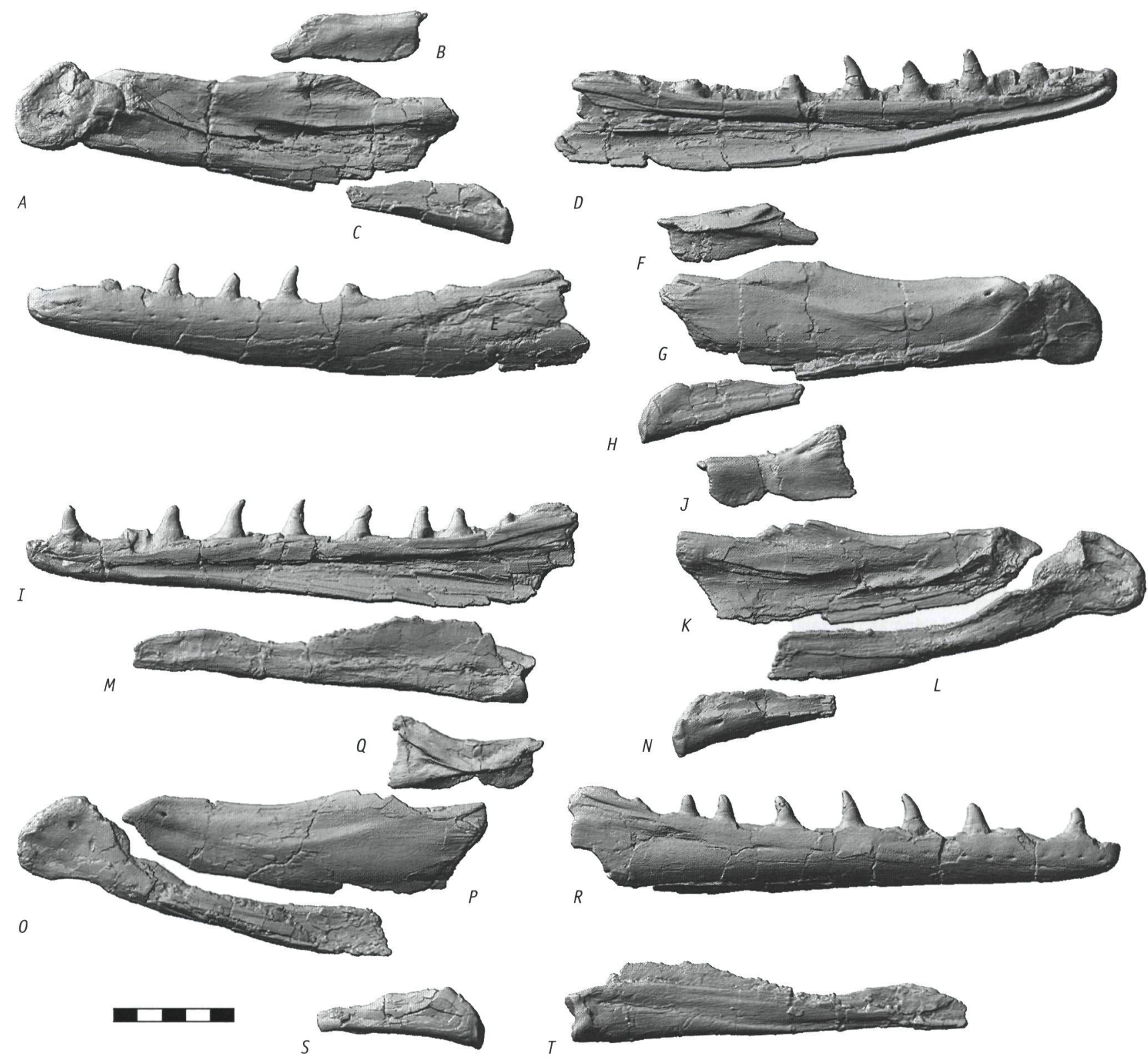

Fig. 7. Mandibles of Russellosaurus coheni $n$. gen., n. sp. (SMU73056), left surangular and articular in A - medial; and G - lateral views; left coronoid in $B$ - medial; and F-lateral views; left dentary in D - medial; and $E$ - lateral views; left angular in $C$ - medial; and $H$ - lateral views; right dentary in $I$ - medial; and $R$ - lateral views; right coronoid in $\mathrm{J}$ - medial; and $Q$ - lateral views; right surangular in $K$ - medial; and $P$ - lateral views; right articular in L-medial; and 0 - lateral views; right splenial in $M$ - medial; and $T$ - lateral views; right angular in $N$ - medial; and $S$ - lateral views. Scale bar equals $5 \mathrm{~cm}$.

Dentary - The dentary is long and slender, the posterior margin slopes slightly anteriorly (Fig. 7D, E, I, R). It has sixteen tooth positions, which are almost circular in cross section, strongly recurved, asymmetrically bicarinate, the smaller tooth area exposed laterally. The teeth have fine medial striations and poorly developed, less consistent lateral striations. The most posterior teeth are the smallest and the longest are in positions 7 - 9. A moderately high medial parapet exposes a pleurodont dentition lingually. Tooth presence follows the pattern $x, 2, x, x, 5, x, 7, x, 9, x, 11, x, 13,14, x, 16$ (where ' $x$ ' indicates shed or missing tooth) and resorption pits are present on the posterolingual surface of the root. The dentary terminates abruptly in front of the anterior tooth position. The anterior terminus of the Meckel's groove extends to a position parallel to the anterior margin of the first tooth. The portion of the dentary forming the ventral margin of the Meckel's groove is thin. There is no trace of a sutured mental articulation. The mandibular branch of the trigeminal nerve and artery enter the posterior dentary at a point just below the dental shelf, the medial portion covered by a medial septum. Laterally, eleven mental foramina form a line parallelling the tooth row and two to three more randomly placed foramina are 
visible anteriorly. Posterolaterally a sulcus, apparently for a tendonal attachment, is visible just below the gum-line and corresponds to a similar structure on the surangular. It probably overlapped the trigeminal canal originating in the surangular, provided protection, and acted as a dorsal hinge.

Splenial - The right splenial is virtually complete, lacking less than a centimetre on its very thin anterior end, evidenced by impressions left in the matrix by the missing portion (Fig. 7M, T). The bone comprises an elongate basal portion from which two laminae, one low and lateral, the other relatively high and medial, embrace the prearticular. Throughout its entire length the two laminae form a channel. The portion of the lateral lamina exposed beneath the dentary occupies approximately half the length of the splenial and terminates anteriorly below the twelfth dentary tooth. The medial lamina is about half again as tall as the lateral wing, has an upper margin that is gently sinusoidally curved and rises to its highest point near the posterior end of the wing. Behind this point, the margin rapidly curves downwards to a level just below that of the lateral wing at the same position, then turns almost horizontally for more than a centimetre before intersecting the posterior margin. There is no dorsal emargination or foramen for the medial exit of the lingual nerve and artery as in Angolasaurus (Antunes, 1964, pl. 15). In posterior view, the articulation for the angular is essentially subrectangular, taller than wide, with the ventral corners uniformly rounded and the lateral side taller than the medial. The face of the articulation is concave in the centre with steep bounding ridges formed by the ventral edges. Dorsolaterally, this bounding ridge is not as pronounced. Dorsally, there is a strong, obtusely angular ridge that originates near the centre of the articular depression and grows wider and taller dorsally. There are no indications of rotational grooving within the articular face, as in Plioplatecarpus. The maximun height of the articulation is $20 \mathrm{~mm}$ and the maximum width is $12 \mathrm{~mm}$.

Angular - The angular splenial articulation is inclined posteriorly in lateral view and is almost teardrop shaped in anterior view (Fig. $7 \mathrm{C}, \mathrm{H}, \mathrm{N}, \mathrm{S}$ ). It receives the prearticular from above in a deep groove. The anterior portion of the groove forms a cleft in the elongate teardrop.

Surangular - The surangular is relatively long and slender, its dorsal margin slightly concave (Fig. 7A, G, K, P). On the midlateral surface, a strong dorsally concave ridge parallelling the dorsal margin is present for attachment of the pseudotemporalis superficialis and adductor mandibulae. The path of the surangular-articular suture curves gently posterodorsally, then turns anterodorsally. It terminates at the middle of the glenoid, then forms an oblique articulation forming an anterior buttress of the glenoid but not participating in the majority of the articulating surface. The suture is slightly interdigitate just below the glenoid. There is a deep sulcus for the posteroventral process of the coronoid. The posterior branch of the mandibular artery enters the surangular within a channel whose dorsal edge articulates with the prearticular process of the articular.

Coronoid - The right coronoid has a poorly developed posterodorsal process and is apparently pathologically deformed (Fig. 7B, F, J, Q). The left coronoid is complete and seems to be normally developed. The dorsal margin is concave with a relatively high posterior process. The anterior half straddles the surangular and slightly overhangs the dentary. The internal posteromedial process inserts into a sulcus on medial surangular.

Articular-Prearticular - The prearticular is long and lightly built and extends anterior to the twelfth tooth position (Fig. 7A, G, L, 0). The retroarticular is ovoid, its long axis oriented posteroventrally and displays a single large foramen on its lateral surface just posterior to the glenoid and approximately one centimetre below the dorsal margin $3.5 \mathrm{~mm}$ dorsoventral height). There is a slight ventromedial curvature of the retroarticular (inferred, corrected for crushing). The articular occupies most of glenoid. It articulates dorsally into a groove on the surangular, medially enclosing a trough-like sulcus on the medial surangular. The articular is separated from the coronoid by medial exposure of the surangular posteriorly, but it may have contacted the coronoid anteriorly.

\section{Phylogenetic relationships}

The specimen shares a close relationship with Plioplatecarpinae (sensu Bell, 1997) by the possession of a large foramen on the lateral retroarticular process, an olfactory canal that is almost enclosed below by a descending process of frontals, basilar arteries that enter the basioccipital floor, and a triangular parietal table. However, compared to derived plioplatecarpines, the new taxon possesses alternative states of the latter two characters in that the basilar arteries enter through a small pair of foramina and exit the basioccipital ventrally and do not send an anterior branch into the basisphenoid, and the sides of the triangular parietal table do not meet anterior to the divergence of the suspensorial rami. Further, the specimen displays a mosaic of plesiomorphic characters present in plesiopedal, halisauromorph and basal mosasaurine mosasaurs (Bell, 1993, 1997). These include narrow frontals, generalised morphology of the quadrates, and high tooth count.

To further ascertain the affinities of Russellosaurus coheni, it was assessed and coded for characters employed by Bell (1997) along with four additional pre-Coniacian taxa. These include Yaguarasaurus columbianus (Páramo, 1994, 2000), Angolasaurus bocagei (Antunes, 1964; Lingham-Soliar, 1994), Haasiasaurus gittelmani (Polcyn et al., 1999, 2003) and Tethysaurus nopcsai (Bardet et al., 2003). Additionally, 
Platecarpus somenensis was removed from the matrix because the available material is not diagnostic (see Appendix A of Bell \& Polcyn (2005) for modified characters and data matrix). The analysis was performed on a matrix of 144 characters and 41 taxa using Paup 4, beta 10 (Swofford, 2002). All characters were treated as unordered and unweighted, and deltran character optimization was employed.

The analysis produced three equally parsimonious trees with a length of 412 with a consistency index (CI) of .429, a homoplasy index (HI) of .570, and retention index (RI) of .757. Figure 8 illustrates the preferred hypothesis of relationships within Mosasauroidea. The results of this analysis vary from Bell's (1997) in a number of respects. First, instability amongst the three trees was limited to basal members of the genus Clidastes. Second, in all trees $R$. coheni, Y. columbianus and T. nopcsai form a clade reconstructed as the sister group to the clade containing Plioplatecarpinae plus Tylosaurinae, and thus provides support for parafamily Russellosaurina (previously referred to as Russellosaurinae; Bell, 1993, 1997). Third, better resolution of basal forms was achieved, with most plesiopedal mosasauroids clustering with established subfamilies. The Trieste aigialosaur reconstructs as the sister taxon of Halisaurus as in Bell (1997); however, Halisaurus plus the Trieste aigialosaur is reconstructed in a more derived position as the sister clade to Russellosaurina and collectively as the sister taxon to Haasiasaurus. Fourth, Dallasaurus turneri (previously referred to as 'the Dallas aigialosaur'; Bell, 1993, 1997) was reconstructed as the sister taxon to Mosasaurinae in all trees and is herein referred to that subfamily. Fifth, Aigialosaurus reconstructs in a basal position prior to the divergence of Mosasaurinae and Russellosaurina. Finally, Opetiosaurus retains its basal position within Mosasauroidea. This arrangement is reminiscent of the findings of Russell (1967, text-fig. 99) in which he illustrated a branching diagram of mosasaur interrelationships, deriving from two distinct lineages of aigialosaurs: (1) a Clidastes-like ancestor giving rise to mosasaurine mosasaurs, and (2) a Platecarpus-like ancestor giving rise to plioplatecarpine and tylosaurine mosasaurs.

\section{Discussion and conclusions}

Although phylogenetic analysis indicates a close relationship between $R$. coheni and $Y$. columbianus, significant distinctions exist. The latter species is approximately 30\% larger and $R$. coheni appears to be a subadult animal; therefore, the possibility that $R$. coheni is a juvenile specimen of $Y$. columbianus was evaluated. The frontal is narrower in $R$. coheni than in Y. columbianus. Bell \& Sheldon (1986) indicate that intracranial allometry was not apparent in a juvenile specimen of Clidastes. Additionally, parametric data recently published by Everhart (2002) indicates minimal intracranial allometry within two species of the genus Tylosaurus. Thus, proportional differences of cranial elements appear to be an

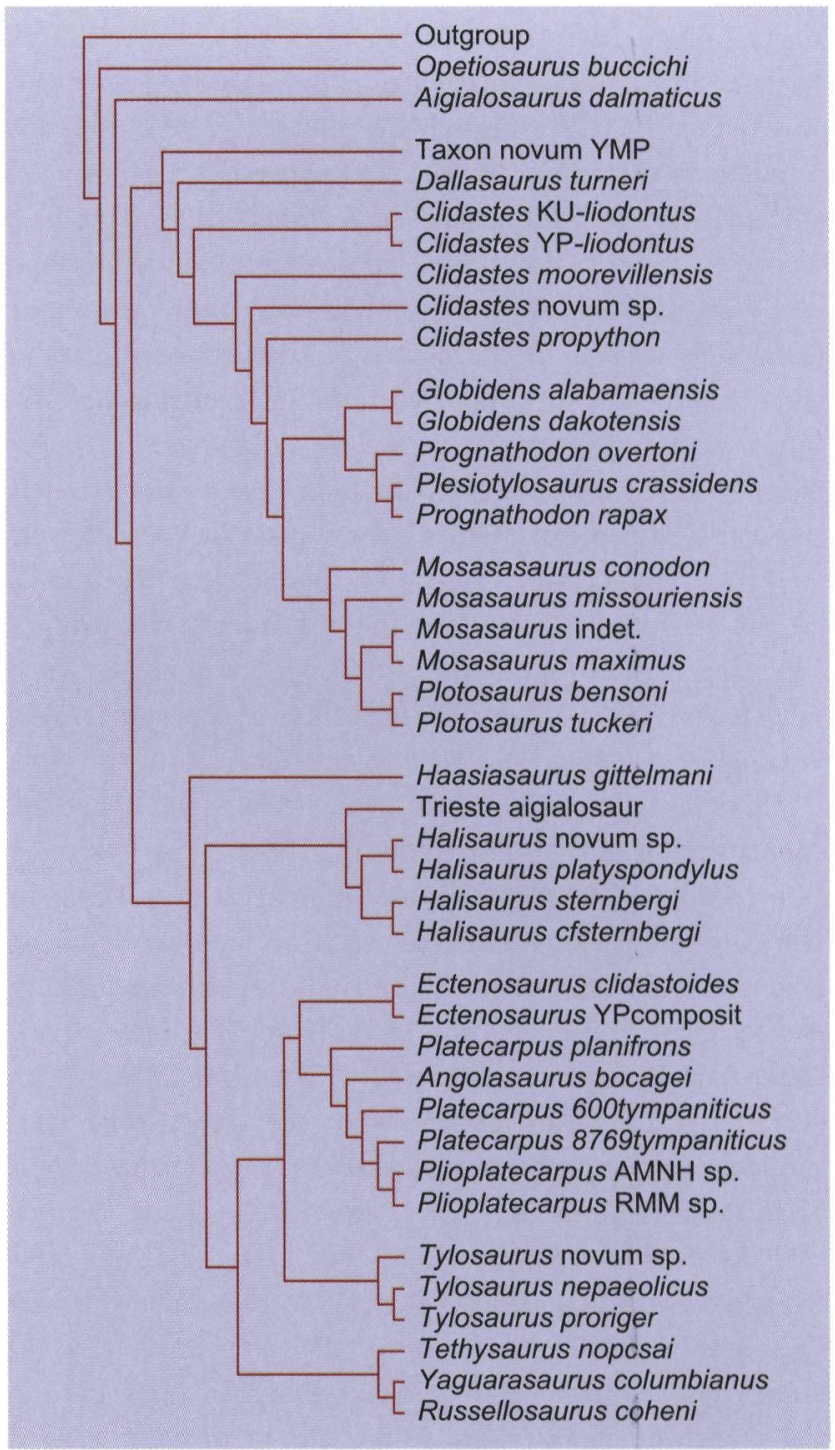

Fig. 8. One of three three equally parsimonious trees with a length of 412, a consistency index (CI) of .429, a homoplasy index (HI) of .570, and a retention index $(R I)=.757$ based on an analysis of 144 characters and 41 taxa.

indicator of taxonomic differentiation. Tooth count is relatively stable within other recognised genera of mosasaurs and is considered to be of phylogenetic utility (Bell, 1993, 1997). Russellosaurus coheni possesses sixteen maxillary teeth and sixteen dentary teeth vs fourteen or fifteen maxillary and fourteen dentary teeth for Y. columbianus (Páramo, 1994, 2000 ). The anterior premaxilla is broad and blunt in $R$. coheni and more sharply pointed in $Y$. columbianus and in dorsal view the premaxillary-maxillary suture is more anteroposteriorly oriented in $Y$. columbianus. The ectopterygoid in $R$. coheni is lightly built and comprises a distinct subrectangular pterygoid process and a slender rod-like jugal process whereas this element in $Y$. columbianus possesses a heavily built subtriangular pterygoid process and a robust rod-like jugal process. There appears to be greater emargination of the frontal by the external nares in $Y$. columbianus. The basilar artery exits as a 
single large foramen in $Y$. columbianus as opposed to multiple smaller, more anteriorly placed exits in $R$. coheni. Presence of longitudinal ridges on ventral basisphenoid in $Y$. columbianus is unique to that taxon. Extreme downgrowth of the pterygoid processes of the basisphenoid in $R$. coheni appears to be a unique character of that taxon. The postorbitofrontal processes in $Y$. columbianus are broad and heavily built. The pineal foramen is located in the centre of the triangular parietal table in $R$. coheni, but is more posterior in $Y$. columbianus. The supraoccipital appears to have a close sutural contact with a posterior downgrowth of the parietal in $Y$. columbianus versus an apparently loose or cartilaginous contact in $R$. coheni with no corresponding downgrowth of the parietal. There is a median cleft in the posterior parietal margin in dorsoventral aspect apparent in $R$. coheni; no such cleft is present in $Y$. columbianus. Thus, unique generic status of the new taxon is justified on the aforementioned distinctions.

Russellosaurus shares certain characters diagnosing Plioplatecarpinae (sensu Bell, 1997); however, some characters seen in other basal forms are also present in Russellosaurus, Tethysaurus and Yaguarasaurus, such as high tooth count, long narrow frontals and nearly straight frontoparietal suture. Photographs of the holotype of Tethysaurus (Bardet et al., 2003) display a strong posteroventral process of the jugal, the characteristic anterior divergence of the suspensorial rami, and the triangular table and parasagittal ridge of the parietal as in Russellosaurus and Yaguarasaurus. They also indicate that the floor of the basioccipital was pierced by three small foramina. These foramina are assumed to be homologous with those seen in Russellosaurus for our phylogenetic analysis. The foramina of the lateral retroarticular process in Russellosaurus and other plioplatecarpines do not appear to be present in Tethysaurus. The entry of the bilobate canal in the basioccipital and the presence of foramina on the lateral retroarticular are characters shared by Russellosaurus and Yaguarasaurus with later plioplatecarpine mosasaurs. This requires reversals in Tylosaurinae given the arrangement recovered in this study (Fig. 9). However, the unambiguous presence of these characters in all other plioplatecarpine mosasaurs raises the possibility that Russellosaurus and Yaguarasaurus are basal members of that clade.

Dallasaurus turneri, a geographically and temporally sympatric species, occupies a basal position in Mosasaurinae. Tethysaurus retains an essentially terrestrial configuration of the girdle elements and limbs (Bardet et al., 2003) as does Dallasaurus (Bell \& Polcyn, 2005) and thus the phylogenetic arrangement presented herein suggests that evolution of a paddle-like configuration of the limbs evolved at least twice within Mosasauroidea.

\section{Acknowledgements}

Our sincere appreciation goes to Mark Cohen, who discovered and generously donated the specimen. We also thank Dr Bruce Welton, Chris Wadleigh, Richard Van Atta, and Richard and Shawn Zach (DPS) for the donation of various specimens, Bill Lowe, Lloyd Hill and John Maurice for their roles in the collection and conservation of the specimen, and Mike Everhart and Louis Jacobs for reviewing this contribution.

\section{References}

Antunes, M.T., 1964. O Neocretácico e o Cenozóico do Litoral de Angola. Junta de Investigações do Ultramar (Lisbon): $255 \mathrm{pp}$.

Bardet, N., Suberbiola, X.P. \& Jalil, N.-E., 2003. A new mosasauroid (Squamata) from the Late Cretaceous (Turonian) of Morocco. Comptes Rendus Palevol 2(8): 607-616.

Bell, G.L. Jr., 1993. A phylogenetic analysis of mosasauroidea (Squamata). University of Texas, Austin, Texas, 293 pp. (unpublished Ph.D. dissertation).

Bell, G.L. Jr., 1997. A phylogenetic revision of North American and Adriatic Mosasauroidea. In: J.M. Callaway \& E.L. Nicholls (eds): Ancient Marine Reptiles. Academic Press (San Diego): 293-332.

Bell, G.L. Jr. \& Polcyn, M.J., 2005. Dallasaurus turneri, a new primitive mosasauroid from the Middle Turonian of Texas and comments on the phylogeny of Mosasauridae (Squamata). In: Schulp, A.S. \& Jagt, J.W.M. (eds): Proceedings of the First Mosasaur Meeting. Netherlands Journal of Geosciences 84: 177-194.

Bell, G.L. Jr. \& Sheldon, M.A., 1986. Description of a very young mosasaur from Greene County, Alabama, Journal of the Alabama Academy of Science 57: 76-82.

Caldwell, M.W., 1995. The pectoral girdle and forelimb of Carsosaurus marchesetti (Aigialosauridae), with a preliminary phylogenetic analysis of mosasauroids and varanoids. Journal of Vertebrate Paleontology 15: 516-531.

Caldwell, M.W., 1996. Ontogeny and phylogeny of the mesopodial skeleton in mosasauroids reptiles. Zoological Journal of the Linnean Society 116: 407-436.

Caldwell, M.W., 2000. On the aquatic squamate Dolichosaurus longicollis Owen, 1850 (Cenomanian, Upper Cretaceous), and the evolution of elongate necks in squamates. Journal of Vertebrate Paleontology 20: 720-735.

Carroll, R.L. \& DeBraga, M., 1992. Aigialosaurs: mid-Cretaceous varanoid lizards. Journal of Vertebrate Paleontology 12: 66-86.

DeBraga, M., 1990, Anatomical and Functional Changes between Terrestrial Varanoid Lizards and Aquatic Mosasaurs, McGill University, Montreal (unpublished Masters thesis).

DeBraga, M. \& Carroll, R.L., 1993. The origin of mosasaurs as a model of macroevolutionary patterns and processes. Evolutionary Biology 27: 245-322.

Everhart, M.J., 2002. New data on cranial measurements and body length of the mosasaur, Tylosaurus nepaeolicus (Squamata; Mosasauridae), from the Niobrara Formation of western Kansas. Transactions of the Kansas Acadademy of Sciences 105: 33-43.

Jacobs, L.L., Ferguson, K., Polcyn, M.J. \& Rennison, C., 2005. Cretaceous $\delta^{13} \mathrm{C}$ stratigraphy and the age of dolichosaurs and early mosasaurs. In: Schulp, A.S. \& Jagt, J.W.M. (eds): Proceedings of the First Mosasaur Meeting. Netherlands Journal of Geosciences 84: 257-268. 
Jacobs, L.L, Polcyn, M.J., Taylor, L.H. \& Ferguson K., 2005. Sea surface temperatures and palaeoenvironments of dolichosaurs and early mosasaurs. In: Schulp, A.S. \& Jagt, J.W.M. (eds): Proceedings of the First Mosasaur Meeting. Netherlands Journal of Geosciences 84: 269-281.

Lingham-Soliar, T., 1988. The mosasaur, Goronyosaurus, from the Upper Cretaceous of Sokoto State, Nigeria. Palaeontology 31: 747-762.

Lingham-Soliar, T., 1994. The mosasaur 'Angolasaurus' bocagei (Reptilia: Mosasauridae) from the Turonian of Angola re-interpreted as the earliest member of the genus Platecarpus. Paläontologische Zeitschrift 68: 267-282.

Páramo, M.E., 1994. Posición sistematica de un reptil marino con base en los restos fosiles encontrados en capas del Cretacico superior en Yaguara (Huila). Revista de la Academia Colombiana de Ciencias Exactas, Fisicas y Naturales 19(72): $63-80$.

Páramo, M.E., 2000. Yaguarasaurus columbianus (Reptila, Mosasauridae), a primitive mosasaur from the Turonian (Upper Cretaceous) of Columbia. Historical Biology 14: 121-131.

Polcyn, M.J., Tchernov, E. \& Jacobs, L.L., 1999. The Cretaceous biogeography of the eastern Mediterranean with a description of a new basal mosasauroid from 'Ein Yabrud, Israel. In: Tomida, Y. \& Vickers-Rich, P. (eds): Proceedings of the 2nd Gondwanan Dinosaur Symposium. National Science Museum Monographs 15: 259-290.

Polcyn, M.J., Tchernov, E. \& Jacobs, L.L., 2003. Haasiasaurus gen. nov., a new generic name for the basal mosasauroid Haasia Polcyn et al., 1999. Journal of Vertebrate Paleontology 23: 476.

Russell, D.A., 1967. Systematics and morphology of American mosasaurs (Reptilia, Sauria). Peabody Museum of Natural History, Yale University, Bulletin 23: 1-241.

Swofford, D.L., 2002. PAUP*. Phylogenetic Analysis Using Parsimony (*and Other Methods). Sinauer Associates, Sunderland, Massachusetts. 